\title{
Cell Calcium Imaging as a Reliable Method to Study Neuron-Glial Circuits
}

\author{
Ricardo Augusto de Melo Reis ${ }^{1 *}$, Hércules Rezende Freitas ${ }^{2}$ and \\ Fernando Garcia de Mello ${ }^{1}$
}

${ }^{1}$ Laboratório de Neuroquímica, Instituto de Biofísica Carlos Chagas Filho, CCS, Universidade Federal do Rio de Janeiro, Rio de Janeiro, Brazil, ${ }^{2}$ Department of Pathology and Laboratory Medicine, MIND Institute, University of California, Davis, Sacramento, CA, United States

\section{OPEN ACCESS}

Edited by: João O. Malva,

University of Coimbra, Portugal

Reviewed by:

Xin Yu,

Max Planck Institute for Biological

Cybernetics, Germany

Fahmeed Hyder,

Yale University, United States

*Correspondence:

Ricardo Augusto de Melo Reis

ramreis@biof.ufri.br

Specialty section:

This article was submitted to

Brain Imaging Methods,

a section of the journal

Frontiers in Neuroscience

Received: 03 June 2020 Accepted: 24 August 2020 Published: 02 October 2020

Citation:

de Melo Reis RA, Freitas HR and de Mello FG (2020) Cell Calcium Imaging as a Reliable Method to Study Neuron-Glial Circuits.

Front. Neurosci. 14:569361. doi: 10.3389/fnins.2020.569361
Complex dynamic cellular networks have been studied in physiological and pathological processes under the light of single-cell calcium imaging (SCCl), a method that correlates functional data based on calcium shifts operated by different intracellular and extracellular mechanisms integrated with their cell phenotypes. From the classic synaptic structure to tripartite astrocytic model or the recent quadripartite microglia added ensemble, as well as other physiological tissues, it is possible to follow how cells signal spatiotemporally to cellular patterns. This methodology has been used broadly due to the universal properties of calcium as a second messenger. In general, at least two types of receptor operate through calcium permeation: a fast-acting ionotropic receptor channel and a slow-activating metabotropic receptor, added to exchangers/transporters/pumps and intracellular $\mathrm{Ca}^{2+}$ release activated by messengers. These prototypes have gained an enormous amount of information in dynamic signaling circuits. SCCl has also been used as a method to associate phenotypic markers during development and stage transitions in progenitors, stem, vascular cells, neuro- and glioblasts, neurons, astrocytes, oligodendrocytes, and microglia that operate through ion channels, transporters, and receptors. Also, cancer cells or inducible cell lines from human organoids characterized by transition stages are currently being used to model diseases or reconfigure healthy cells in terms of the expression of calcium-binding/permeable molecules and shed light on therapy.

Keywords: calcium imaging, neuron-glia, ATP, glioblastoma, fluorescent indicator

\section{INTRODUCTION}

Since the revolutionary work of Camilo Golgi, Santiago Ramon y Cajal, and Charles Sherrington at the turn of the twentieth century, scientists have attempted to correlate structure and function to understand the nervous system. At that time, cells were labeled with the technique of silver impregnation, discovered by Golgi in 1873 and later applied by Cajal to almost every part of the brain, from 1887 until the rest of his life. At the same time (1882-1883), Sydney Ringer described the properties of a physiological solution acknowledging the role of $\mathrm{Ca}^{2+}$ 
(in addition to $\mathrm{Na}^{+}$and $\mathrm{K}^{+}$) (Ringer and Buxton, 1887), essential to contraction and the observed variations of ventricular volume of excised frog heart (Miller, 2004). Around 1910, Sherrington conceptualized the synapse, only deeply comprehended in terms of active zones around the 1950s, with the development of the electronic microscope. Electron-dense pre-synaptic sites were characterized and shown to host multifunctional proteins, including calcium channels. In parallel, the work of brilliant electrophysiologists such as John Eccles, a defendant of the concept of electrical synapse, and the pillars of bioelectrogenesis and action potential, Alan Hodgkin, Andrew Huxley, Bernard Katz, Ricardo Miledi, among others, added another level of signaling in modern neurophysiology.

Cellular neuroscience emerged in the last half-century as a merge of anatomy, histology, physiology, neurochemistry, cell biology, and behavioral sciences to gain information on the rules of neural ensembles and behavior. Lately, questions evolved with data revealed from in vitro fluorescence and/or confocal microscope and/or in vivo non-invasive high-resolution imaging techniques as the two-photon and/or lightweight miniaturized microscopy that permit optical recordings in freely moving animals for weeks.

Cellular networks can now be visualized with powerful imaging methods using advanced statistics to allow dynamic molecular messages that drive structure and function with fluorescent shuffled reporters (Lichtman et al., 2008). Pharmacological approaches based on functional proteomics add several layers of complexity, evaluated through optogenetics (Kim et al., 2017) or in combination with electrical or optical recordings, providing powerful strategies to alter the neural function and gain behavioral data (Frackowiak and Markram, 2015). This will soon lead to further details on the plasticity and the adaptation of the brain to understand still intangible fields such as cognition and consciousness (Cook, 2008). Here, we will focus on the properties of $\mathrm{Ca}^{2+}$ signaling dynamics related to membrane proteins found virtually on every single neural cell, but due to limitation, it will be restricted to selective models.

Single-cell calcium imaging (SCCI) is a versatile methodology used to visualize calcium shifts, from extracellular or intracellular stores, associated with a profile of molecules selectively expressed on living individual cells. Calcium has a central role on almost every cellular task, as a messenger ion and/or interacting with a multitude of binding proteins, adjusting several activities, e.g., gene transcription, cell birth, proliferation, migration, signaling/excitation/contraction, cell growth, metabolism, cytoskeletal dynamics, differentiation, synaptic transmission and plasticity, survival, and death (Carafoli and Krebs, 2016; Islam, 2020). Calcium concentration in the extracellular space is $\sim 1.8-2.5 \times 10^{-3} \mathrm{M}$, at least $2 \times 10^{4}$ higher than in the cytosolic compartment (typical resting levels $\sim 1-2 \times 10^{-7} \mathrm{M}$ ). The expression of calcium-permeable channels, transporters, receptors, and effector molecules is essential to understand spatiotemporal signaling in living cell compartments. Calcium imaging evaluates intracellular $\mathrm{Ca}^{2+}$ dynamics that originated with the development of calcium dyes such as 1,2-bis(o-aminophenoxy)ethane-N,N,N'N'tetraacetic acid from the laboratory of Roger Y. Tsien, with high selectivity against magnesium and protons (Tsien, 1980) and later improved as selective $\mathrm{Ca}^{2+}$ indicator, "quin2", studied inside intact lymphocytes (Tsien et al., 1982). Lipophilic groups added [acetoxymethyl or acetate ester (AM) groups] to the charged indicators gave a membrane-permeant property and hidden charges, allowing cleavage by constitutively expressed intracellular esterases. These sensors show stronger fluorescence (intensity increases up to 30-fold) and better affinity for $\mathrm{Ca}^{2+}$ and selectivity against $\mathrm{Mg}^{2+}$ in the presence of $\mathrm{Ca}^{2+}$ shifts (Grynkiewicz et al., 1985). The first six dyes generated [from which fura-2 (Figure 1A) and indo-1 are the ratiometric] [measure free $\mathrm{Ca}^{2+}$ concentration with $\mathrm{Ca}^{2+}$-free and $\mathrm{Ca}^{2+}$ bound forms having two distinct peaks (Figure 1B)] prototypes, based on the fluorescence intensity detected on two wavelengths (Rudolf et al., 2003; Bruton et al., 2020), and are widely recognized to track calcium shifts within cells (Figures 1CF), from intracellular or extracellular sources. The development of better fluorescent microscopes and computation methods yielded high-resolution optical data with a high degree of spatial and temporal resolution to image calcium signaling on living cells and organisms.

The use of genetically coded calcium indicators (GECI) allowed the study of cellular structure/function to match behavior responses. GECIs have been developed as fused proteins to monitor the spatiotemporal patterns of intracellular $\mathrm{Ca}^{2+}$ dynamics in functional compartments of living organisms. This strategy has been used from Drosophila to the intact brain of transgenic rodents and not only in the cytoplasmic environment but also in organelles such as the mitochondria or the endoplasmic reticulum. Excellent recent reviews are available, so we will not extend on this matter (Inoue, 2020). Briefly, to overcome obstacles in dye loading faced by organic indicators and other variabilities on the lack of cell-type selectivity, chimeric protein has been engineered and named "chameleons" (Miyawaki et al., 1997) based on the color change of fluorescent proteins fused to a $\mathrm{Ca}^{2+}$ binding protein (usually calmodulin or troponin C) and M13 [a peptide with a primary sequence based on the skeletal muscle myosin light chain kinase (residues 577-602). This peptide acts as a spacer and binds to $\mathrm{Ca}^{2+}$, modifying the conformation from a weak to strong fluorescence complex. Fluorescence resonance energy transfer is based on $\mathrm{Ca}^{2+}$ binding and conformation change of calmodulin around the M13 domain. As an example, GCaMP acts a high-affinity $\mathrm{Ca}^{2+}$ probe prototype composed of a single green fluorescent protein (Nakai et al., 2001). Variations (GCaMP3, GCaMP5, and GCaMP6) have been prepared, which are converted from green to red following exposure to blue-green light at 450-500 nm (Ai et al., 2015).

A current challenge faced with GECI live imaging is related to the identification of specific subsets of active neurons within a larger cell population. Accomplishing this task is important to understand ensemble responses and to improve the visualization of signal integration across multiple brain regions. Although several efforts were able to ensure a somewhat automated processing of these imaging results through classic machine learning techniques (Mukamel et al., 2009; Kaifosh et al., 2014; 

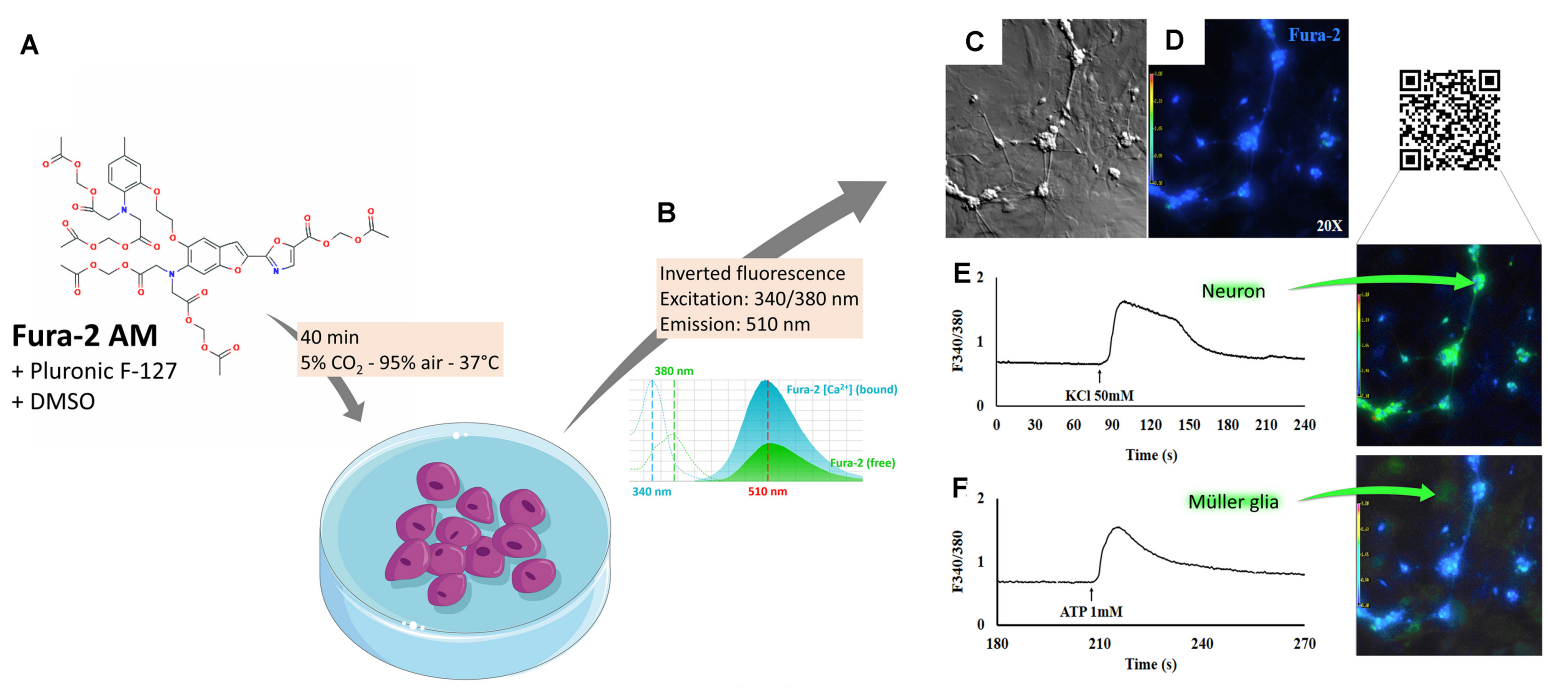

in vitro

in vivo

G



H

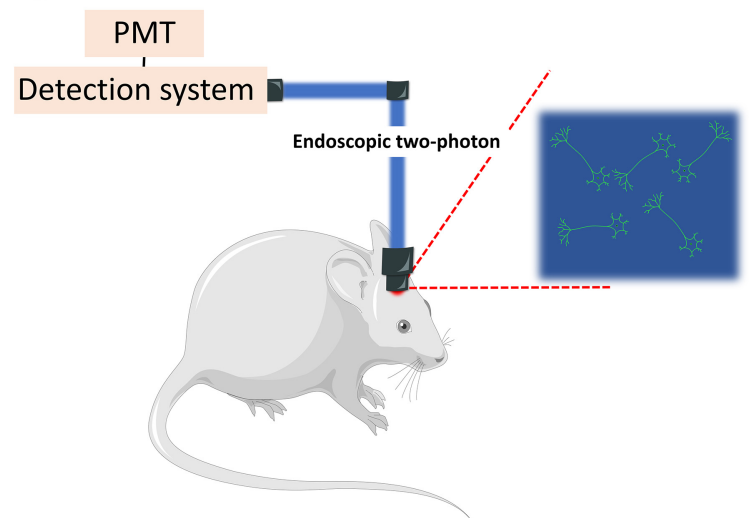

FIGURE 1 | Detecting intracellular calcium changes through single-cell calcium imaging. Single-cell calcium imaging evaluates intracellular Ca ${ }^{2+}$ dynamics through calcium probes as Fura-2 AM (A), a lipophilic acetate ester (AM) that permeates the cell membrane in an apolar environment (DMSO + pluronic F-127), allowing cleavage by intracellular esterases. These sensors show stronger fluorescence and better affinity for $\mathrm{Ca}^{2+}$ and selectivity against $\mathrm{Mg}^{2+}$ in the presence of $\mathrm{Ca}^{2+}$ shifts (B). Neurons and glia in bright field (C) or under fluorescence (D) when activated by $\mathrm{KCl} 50 \mathrm{mM}$ (E) or ATP 1 mM (F) show selective responses. In parallel, the use of inducible genetically encoded calcium indicators and a variety of detection systems made probing neural cell behavior in live animals a possibility. Through a photoreceiver, it is possible to detect changes in cell fluorescence as the animal is awake and freely behaving. An optimized version of this technique can be obtained through multi-site photometry (G), which allows for the detection of spatiotemporal changes as the animal responds to varying environmental patterns. In this method, signals are detected by a complementary metal oxide semiconductor (CMOS) camera. Direct bidimensional fluorescence can be detected with the use of one-photon microendoscopes, capable of imaging a region of interest (ROI) inside the living brain, which in turn is detected by a CMOS camera. Two-photon endoscopes can be used to generate a high-fidelity view of a given ROI. In this case, images are generated after detection by photomultiplier tubes $\mathbf{( H )}$.

Guan et al., 2018), current approaches are now entering the realm of convolutional neural networks, which can be used in a 3D architecture to segment active neurons on different layers of the same imaging target (Soltanian-Zadeh et al., 2019). Also, accessible algorithms for imaging motion correction have been recently developed and can be used to improve the output quality of automated segmentation networks (Pnevmatikakis and Giovannucci, 2017).

It is interesting to notice that, while the analysis of live $\mathrm{Ca}^{2+}$ imaging data is becoming increasingly accessible and automated through a large array of online resources, the in vivo experiments demand progressively more sophisticated tools, either to improve field-of-view resolution or to increase the number of simultaneous detections from different brain regions. The use of confocal and multiphoton laser scanning microscopy helped to extend to the larger scale, obtaining data on organ systems, from small GECI-expressing transparent alive invertebrates to awake transgenic mammals (Russell, 2011). Through a photoreceiver, it is now possible to detect changes in cell fluorescence in different in vivo models, as imaging for somatosensorial or visual inputs inducing synaptic plasticity on the dendritic spine patterns on cortical neurons or calcium 
imaging in awake and freely behaving animals (Grienberger and Konnerth, 2012). One exciting possibility would be the integration of multiple neuroimaging methods, combining low spatiotemporal fidelity from functional magnetic resonance imaging (fMRI) with multiple-site photometry (Figure 1G). Several groups have reported simultaneous acquisition of blood oxygen level-dependent (BOLD) fMRI, regularly used for noninvasive functional neuroimaging, combined with chronically implanted optical fiber, which allow data acquisition of identified cells from transgenic models or through viral electroporation delivered with GCaMP6 (Schlegel et al., 2018), and understand the relationship of neural and vascular signals (Albers et al., 2018). The advantage of animals placed in an MRI scanner coupled to a fiber photometry through a silicon photo multimeter is the prevention of electromagnetic interference seen in electrophysiological recordings during MRI scanning (Logothetis et al., 2001). The increased popularity of this technique came with the development of the multi-channel fiber photometry system to simultaneously monitor neural activities in several brain areas of an animal or in different animals (Guo et al., 2015). It was initially prepared to explore this correlation in rat somatosensory cortex, where forepaw stimulation evoked fast calcium signals of neuronal origin (Schulz et al., 2012) or, as reported, slower calcium signals derived from astrocyte networks. Coupling of GCaMP6-based calcium signal to neural activity produces a novel opportunity with a reproducible temporal relationship, validated, for example, with a visual stimulation experiment, during which robust increases of both calcium and BOLD signals were observed in the superior colliculus of rats (Liang et al., 2017). A following investigation demonstrated that these signals emerge in a region-specific pattern from the SC and the lateral geniculate nucleus (Tong et al., 2019). This strategy has also permitted the mapping of neuronal circuits in the whole mouse cortex, yielding a connective map spanning several cortical subregions (Lake et al., 2018; Schlegel et al., 2018). Today it is possible to study anesthetized or freely behaving animals and probe calcium signals in a variety of brain regions during development, aging, or disease (Wright et al., 2017; Schlegel et al., 2018). An optimized version allows multi-fiber photometry and optogenetic perturbations across many regions in the mammalian brain (the authors managed to detect GCaMP6m-generated $\mathrm{Ca}^{2+}$ fluorescence from striatal, thalamic, hippocampal, and cortical areas). In this sense, the spatiotemporal changes of neuronal activity are registered as a go/no-go texture discrimination task runs on awake mice responding to varying environmental patterns (Sych et al., 2019). Alternatively, in vivo astrocytic microdomains show spatially restricted synchronized calcium transients that last a few seconds upon activation of transmitter receptors, observed in both anesthetized and awake animals [reviewed in Nimmerjahn and Bergles (2015)]. In this method, signals are detected by a complementary metal oxide semiconductor (CMOS) camera. Direct bidimensional fluorescence can be detected with the use of a one-photon microendoscope, capable of imaging a region of interest (ROI) inside the living brain, which in turn is detected by a CMOS camera. Two-photon endoscopes can be used to generate a high-fidelity view of a given ROI. In this case, images are generated after detection by photomultiplier tubes
(Figure 1H). In relation to the astrocytic compartment, data on GCaMP-mediated $\mathrm{Ca}^{2+}$ optical fiber recordings described a brain-state dependency of both astrocytic $\mathrm{Ca}^{2+}$ and BOLD fMRI signals (Wang M. et al., 2018). Distinct $\mathrm{Ca}^{2+}$ signals combined with positive BOLD signals and intrinsic astrocytic $\mathrm{Ca}^{2+}$ signals coupled with negative BOLD signals were reported. Indeed recent data from anesthetized transgenic mice expressing G-CaMP7 in astrocytes allowed the extraction of patterns and the reconstruction of cortical areas inserted within spontaneous activity as the functional connectivity maps for the individual mice (O'Hashi et al., 2019). Confined, asynchronous, and spontaneous $\mathrm{Ca}^{2+}$ signals are commonly seen in fine astrocyte processes. As astrocytes are key elements regulating brain energy metabolism (Oheim et al., 2018), the way molecules signal and exchange metabolites in the neuron-glia-vascular circuitry and the concept of $\mathrm{Ca}^{2+}$ waves on microdomains will be greatly improved under the combination of powerful methodologies of calcium recording with fMRI.

One could also apply diffusion tensor imaging measurements, especially fractional anisotropy, with fMRI-BOLD responses to obtain coupled microstructural and functional imaging data (Warbrick et al., 2017). Data could be correlated, a posteriori, with chronic multi-site live calcium fluorescence for spatiotemporal measurements of neural activity. The knowledge acquired from such efforts would certainly be useful to corroborate molecular and histological results, strengthening the mechanistic inferences extracted from data.

Different mechanisms approaching external (channels, receptors, transporters, and exchangers) or internal (endoplasmic reticulum, calciosomes, vesicles) sources, using multiple steps and messengers/signaling molecules/binding proteins, virtually in every in vitro or in vivo cell, can be studied, and due to the scope and the space limitations of this review, we can only exemplify a few. Data shown are on the central and peripheral nervous system (retina and dorsal root ganglia and connections), neurons and glia population, glioblastoma, and cell lineages derived from human organoids.

\section{RETINA, A CENTRAL MODEL}

The retina is frequently chosen as a model to study interactions between neural cells due to its unique disposition in layers, from the embryonic to the final mature structure; as the retina develops, the environment changes, so extrinsic factors (transmitters, growth factors, extracellular matrix, and other mediators) interact with the genetic program modifying intrinsic transcription factors, so each cell leaves the cycle chronologically defined (Hatakeyama and Kageyama, 2004); retinal progenitors are multipotential, and region cell-cell interactions imply precise differentiation in a way that first retinal ganglion cells (RGCs), cone, and amacrine emerge from early-born progenitors, and then photoreceptors, bipolar, and Müller glia develop from late-born progenitors (Turner and Cepko, 1987). The vertical or radial axis, made by photoreceptors-bipolarganglion cells, is excitatory, while the horizontal or lateral axis, composed by horizontal and amacrine cells, is largely 
inhibitory (Barnstable, 1993). Photoreceptors release glutamate in the dark, which activates calcium-permeable ionotropic AMPA/NMDA receptors on OFF-type bipolar cells, while the activation of metabotropic glutamatergic type 6 receptor and ionotropic receptors, among others, mediates ON-type bipolar cell activity (Yang, 2004). $\mathrm{Ca}^{2+}$ imaging studies have been used to detail network properties in ex vivo retinal preparations and revealed a variety of responses on bipolar cells (at least eight different clusters) in terms of $\mathrm{Ca}^{2+}$ shifts in the axon terminals. On the other hand, activation of glutamatergic extrasynaptic NMDA receptors present in the rod pathway show increases in $\mathrm{Ca}^{2+}$ dendritic levels in both AII and A17 amacrine cells, postsynaptically at rod bipolar dyad synapses (Veruki et al., 2019). The depolarization of ganglion cells by voltage-dependent calcium channels (VDCC) contributes to soma and dendritic $\mathrm{Ca}^{2+}$ increases (Sargoy et al., 2014). These are a few examples on how live calcium imaging details the complex retinal signaling network. Based on two-photon calcium imaging, clustering of more than 11,000 mice RGC recordings shows that more than 30 functional channels are channeled (Baden et al., 2016). Recently, chronically stable in vivo recordings from RGCs in awake mice were reported using a genuine epiretinal-implanted 16-channel mesh electronic probe (Hong et al., 2018) delivered non-surgical intravitreally using syringe-injectable. Orientation-selective RGCs were stably registered between recording sessions, 7 days apart, implicating that individual cells can be tracked for 2 weeks.

Retinal neural cells (neurons, glia, and progenitors) can be phenotypically identified when matched in terms of calcium imaging (De Melo Reis et al., 2011). Progenitors cells usually express the intermediate filament marker nestin and are activated by muscimol, a $\mathrm{GABA}_{A}$ receptor-channel agonists in immature networks. The electrochemical gradient for $\mathrm{Cl}^{-}$favors activation due to high intracellular $\mathrm{Cl}^{-}$levels; in this sense, the expression of $\mathrm{K}^{+}$-coupled $\mathrm{Cl}^{-}$transporter $\mathrm{KCC} 2$ is correlated with the modification of GABAergic transmission, switching during development from excitation on progenitors to inhibition on mature GABAergic neurons (Ganguly et al., 2001).

The neuron-glia circuits in the developing retina are shaped by light and sensed by intrinsically photon-detecting retinal ganglion cells, which are coupled electrically to other ganglion cells in a network (Sekaran et al., 2003). Beyond phototransduction, cones and rods regulate important physiological activities (circadian cycle, pupillary reflex, light sensing), which are frequently dependent on dopamine signaling (Caval-Holme et al., 2019). The dopaminergic system is one of the first phenotypes to be expressed in the developing retina (Reis et al., 2007), and dopamine is a potent modulator of spontaneous neural activity and gap junction coupling. Markers for young (doublecortin, $\beta_{I I I}$-tubulin, and PSA-NCAM) and mature (MAP-2) retinal neurons are associated with $\mathrm{KCl}$ depolarizing cells (due to the expression of VDCC) [reviewed by Catterall (2000)]; retinal neurons are activated by ionotropic glutamatergic receptors, NMDA (Veruki et al., 2019), AMPA, or kainate (Okada et al., 1999; De Melo Reis et al., 2011; Passos et al., 2019). Some of these responses are modulated by cyclic AMP, which is induced by dopamine, adenosine, and PACAP receptors and functions as a differentiating factor for dopaminergic retinal cells in the chick (Guimaraes et al., 2001) or rat retina (Varella et al., 1999). Cannabinoid receptors present on neurons and glia (Kubrusly et al., 2018) on the avian retina also contribute to the regulation of different outputs such as GABA release, calcium entry, and cAMP mobilization.

Müller cells are the main glial element in the retina, which intermingles with most, if not all, neurons in this tissue. These cells are active players (de Melo Reis et al., 2008) that transverse from the inner to the outer limiting membranes, spanning the whole retinal length, and control numerous activities such as osmotic (solute and water composition in the extracellular space), metabolic (glutamate-glutamine cycle), signaling (trophic factors and mediators), synaptic (release of transmitters), regulation of plasticity (Reichenbach and Bringmann, 2013), and response to excitotoxicity (Schitine et al., 2015). Müller cells are categorized by the expression of glutamine synthetase and glial fibrillary acidic protein, among other markers, and are activated by high concentrations of ATP due to the expression of purinergic calcium-permeable P2X7 receptor-channel, among others (De Melo Reis et al., 2011; Faria et al., 2017). ATP has many signaling and metabolic functions in the retina; it induces ionic waves through gap junctions and is involved with neuronal cell death (Metea and Newman, 2006; Reichenbach and Bringmann, 2016), while metabotropic (Keirstead and Miller, 1997) or ionotropic glutamatergic receptors on Müller glia also contribute to waves that depend on the nature of other transmitters involved (Rosa et al., 2015). Recent data have shown that progenitors from the embryonic avian retina unresponsive to ATP (Figure 2A) differentiate into neurons (activated by $\mathrm{KCl}$ or glutamate) or glia (activated by ATP) in a cannabinoid-rich environment (Figure 2B). Calcium shifts induced by ATP in avian Müller glia increased up to $30 \%$ in early retinal cells when cannabinoid receptors $\mathrm{CB} 1$ and $\mathrm{CB} 2$ are activated by the cannabinoid agonist WIN 55,212-2 (Figure 2C) (Freitas et al., 2019). Alternatively, a decrease in the number of glutamate-, GABA, and $\mathrm{KCl}-$ responsive cells (neurons and progenitors) was reported. Instead of differentiating, some progenitors die (D) due to the activation of death-inducing pathways (Figure 2D).

Müller cells control oxidative species as they participate in glutathione (GSH) synthesis as astrocytes do in the cortex. GSH is the main glial antioxidant found at a greater millimolar concentration when compared to neurons, which in turn show a much higher (10:1) ascorbate concentration compared to glia (Rice and Russo-Menna, 1998). GSH has been shown to induce selective $\mathrm{Ca}^{2+}$ shifts in Müller glia in a P2X7-dependent manner, a process that induces GABA release (Freitas et al., 2016), possible to strengthen retinal neuroprotection (Freitas and Reis, 2017). Interestingly, in a recent study where the P2X7 receptor was deleted, the basal GSH levels were decreased without altering GSH synthetic enzyme expression in the mouse hippocampus, a process linked to the glutamate-glutamine cycle and neutral amino acid transporters (Park and Kim, 2020).

The Müller glia has been gathering attention due to its proliferative properties after retinal injury and activation of stem/progenitor cell phenotype, allowing a return to the cell cycle and eventually differentiating into functional neurons. This has 


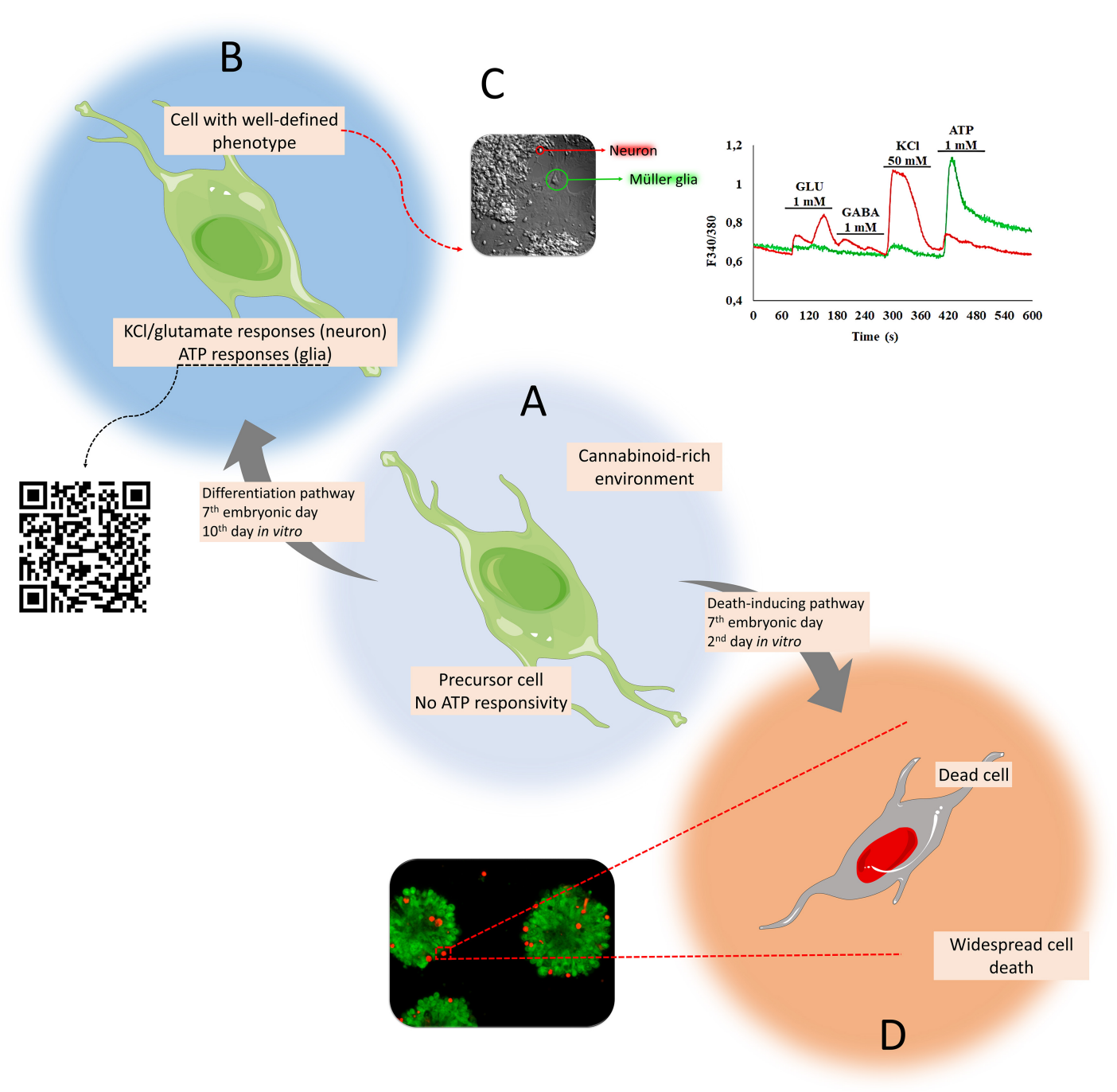

FIGURE 2 | Matching cell phenotypes with calcium signaling activated by P2X7 receptors in retinal cells in culture. Progenitors unresponsive to ATP (A) differentiate into neurons (activated by $\mathrm{KCl}$ or glutamate) or glia (activated by ATP) in a cannabinoid-rich environment (B). Emerging calcium shifts induced by ATP are exclusive to Müller glia (green trace), primed by the early cannabinoid receptor activation (with WIN 55,212-2). On the other hand, neurons are activated by KCl and glutamate (red trace) (Freitas et al., 2019) (C). Instead of differentiating, some progenitors die (D) due to the activation of death-inducing pathways [bottom panel: live (calcein, green) and dead (ethidium homodimer-1, red)].

been shown for neurogenin 2 or ASCL1, transcriptional factors that, when nucleofected onto Müller glia, were reprogrammed into inducible neurons (Guimaraes et al., 2018), functionally monitored in terms of calcium imaging. This strategy has been used by many groups to partially restore vision in different animal models (Hampton, 2018).

Retinal information flows to the thalamus and the primary visual cortex (V1). Pyramidal cells in layers 2/3 were evaluated through two-photon $\mathrm{Ca}^{2+}$ imaging in GECIexpressing transgenic mice so excitatory and inhibitory neuron synchronization could be studied during the wakefulness of the animals (Knoblich et al., 2019). Calcium imaging data combined to in vivo targeted electrophysiology gave within-type cross-correlation coefficient (CC) profiles, which were used to characterize different populations of interneurons, parvalbumin, and VIP characterized as highly active and homogeneously synchronized; alternatively, somatostatin interneurons were subdivided into two populations, one spontaneously active, but uncorrelated to neighbor cells (Knoblich et al., 2019). These populations were differently modulated by locomotion, adding a functional perspective to neuronal cell typing.

\section{SUBVENTRICULAR ZONE}

The subventricular zone (SVZ) is considered as one of the main neurogenic niches in the brain (together with the subgranular zone), where the continuous proliferation of stem cells is actively balanced to generate progenitors, neurons, astrocytes, and oligodendrocytes (Eiriz et al., 2011). Each type of cell can be 
phenotypically identified based on selective markers associated with distinct mechanisms of $\mathrm{Ca}^{2+}$ entry, i.e., dependent on VDCC fast depolarization induced by $\mathrm{KCl}$ on neuroblasts and neurons (Schitine et al., 2012), coupled to metabotropic histamine receptors on progenitors, or modulated by thrombin through the protease-activating receptor on oligodendrocytes (Xapelli et al., 2013, 2014).

\section{SENSORIAL STIMULI, FROM DRG TO CENTRAL PROJECTIONS}

Somatosensorial information combine different modalities such as pain, heat, touch, proprioception, and others by stimulation of peripheral receptors in pseudo-unipolar myelinated and unmyelinated first-order dorsal root ganglia (DRG) neurons; upon sensorial transduction, neural codes are generated as action potential patterns to cell bodies and then to synapses onto secondary neurons located in well-organized Rexed laminae of the spinal cord dorsal horn [reviewed in Peirs and Seal (2016)]. Parallel fibers carrying fast $\left(A_{\text {alpha }} / A_{\text {beta }}\right.$, touch, and proprioception) or slow $\left(A_{\text {delta }} / C\right.$, temperature, and pain) submodalities flow to the thalamus and then to several brain areas.

Locally, the transient receptor potential acts as a nonselective cation channel family, whose vanilloid member (TRPV) depolarizes unmyelinated sensory neurons in the presence of capsaicin to temperature and painful thermal stimuli (Caterina et al., 1997; Peirs and Seal, 2016). Alternatively, ASIC1, acid-sensing ion channel 1, a member of the ASIC family of proteins and part of the degenerin/epithelial sodium channel (DEG/ENaC) superfamily, is expressed in large sensory myelinated neurons (Peirs and Seal, 2016).

Calcium imaging has been employed to DRG and dorsal horn neuron co-cultures to understand the mechanisms behind synaptic transmission coded by $A_{\text {delta }}$ (mechanical and thermal nociception) and C-fibers (high-intensity polymodal stimuli). It was shown that $\mathrm{Ca}^{2+}$ influx through NMDA receptors induced by glutamate depolarizes dorsal horn neurons (Ohshiro et al., 2007). Schwann and satellite cells interact closely with DRG neurons. At the cellular level, $\mathrm{KCl}$ and ATP activate selectively neurons and glia, respectively (Ribeiro-Resende et al., 2014). VDCC are expressed in postnatal primary sensory neurons, while purinergic receptors are broadly expressed in all major classes of glia, including Schwann cells. Indeed purinergic signaling controls many important functions in the neuro-glia compartment in the DRGs such as proliferation, motility, survival, differentiation, and myelination (Fields and Burnstock, 2006). The use of two-photon $\mathrm{Ca}^{2+}$ imaging, $\mathrm{Ca}^{2+}$ indicators, and/or GECI allow high-resolution measurements with detailed functions of different cell types in DRG, for instance, a particular group of neurons (11 to $33 \mu \mathrm{m}$ in diameter) is activated by an increase in temperature in the animal hind paw (Anderson et al., 2018). Besides that, freely behaving mice injected with plantar formalin had a DRG neuronal activity (Figure 3) associated with phasic pain behavior (Chen et al., 2019). This activity persisted for 5 weeks as a hallmark of neuronal hyperactivity associated with ongoing pain. Classical cannabinoid G protein receptors (CB1 and CB2) have been studied in addition to TRPV1 in DRG neurons to evaluate how endocannabinoids can control pain (Millns et al., 2006). $\mathrm{Ca}^{2+}$ influx through purinergic, carbachol-activating muscarinic or TRPV1 receptors increases anandamide synthesis within cells (Ahluwalia et al., 2003) and activates both TRPV1 (van der Stelt et al., 2005) and cannabinoid receptors. CB1 receptors co-localized with purinergic receptors in DRG smalldiameter neurons control pain by anandamide and involves the modulation of $\mathrm{P} 2 \mathrm{X} 3$ receptor in the primary afferent neuron (Oliveira-Fusaro et al., 2017).

Neurons and glia (visualized as ramified processes and in contact with blood vessels, labeled as SR101+) were also studied in response to heat/cold stimuli in the superficial dorsal horn from anesthetized mice (Johannssen and Helmchen, 2010; Ran et al., 2016). The authors reported different overlapping neurons on dorsal horn ensembles activated by cutaneous stimulation in freely behaving mice, while it was reported that large-scale coordinated calcium responses were generated in astrocytes in response to intense, but not weak, sensory inputs (Sekiguchi et al., 2016). On the other hand, amygdala has also received attention as a hub in the pain matrix, as the basolateral part of the amygdala contributes to the negative affective perception of unpleasant pain (Corder et al., 2019), and P2X7 receptor acts in the modulation of neuropathic pain (Hu et al., 2020). Interestingly, the role of general anesthetics on calcium imaging in awake head-restrained mice was studied, and a combination of ketamine/xylazine, isoflurane, and urethane abolished calcium responses in neocortical astrocytes, modifying synchronized widespread transients related to arousal in awake animals (Thrane et al., 2012). Effects were associated with inositol 1,4,5triphosphate type 2 receptor but independent of glutamatergic or purinergic signaling.

Microglia, the immune resident cells in the nervous system, and monocyte-derived macrophages derived from the peripheral circulation have significant and distinct roles in neuroinflammation, injured spinal cord (David and Kroner, 2011), or/and progression of neurological and neuropsychiatric diseases (Chen et al., 2018; Tvrdik et al., 2019). Spinal cord lesion is associated with secondary network damage through inflammation, ischemia, edema, generation of reactive oxygen species, and excitotoxicity (Kroner and Rosas Almanza, 2019). Calcium shifts activated by purines, through P2X receptors, particularly P2X7 and P2X4, mediate neuropathic pain. Indeed activation of microglia by ATP contributes to tactile allodynia in the spinal cord (Tsuda et al., 2003), and microglia-neuron interactions are greatly affected in male, but not female, mice, caused by peripheral nerve injury. Inhibition of purinergic $\mathrm{P} 2 \mathrm{X} 4$ receptors decreased pain hypersensitivity in male rats only (Mapplebeck et al., 2018). The microglia activated by ATP also releases brain-derived neurotrophic factor (BDNF) on lamina I neurons that change the polarity of currents activated by GABA, a major effect after peripheral nerve injury (Coull et al., 2003). As BDNF is an important player between microglia and neurons, this might represent a therapeutic strategy for treating neuropathic pain (Coull et al., 2005). 
A

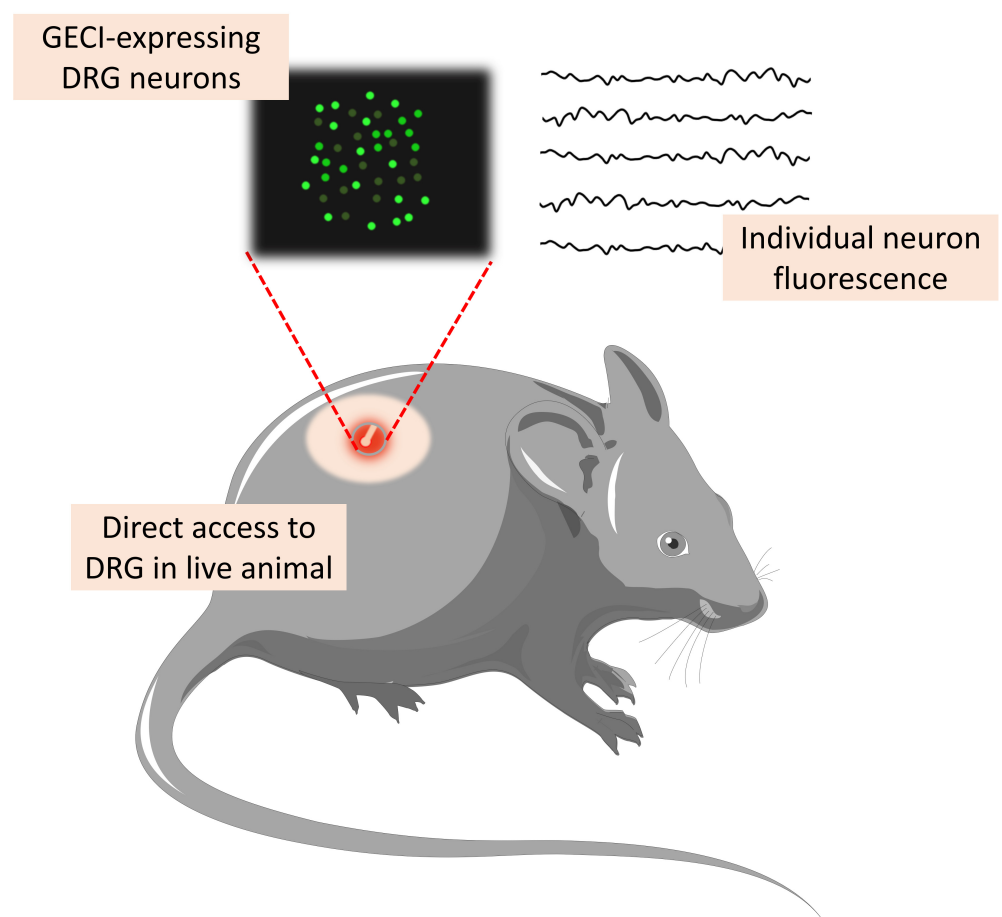

B


FIGURE 3 | Recording dorsal root ganglia (DRG) cells from awake freely moving animals. Genetically coded calcium indicators (GECls), which sense the concentration of $\mathrm{Ca}^{2+}$, allow for measurements of different cell types (A). Freely behaving mice injected with plantar formalin showed DRG neuronal activity associated with phasic pain behavior (Chen et al., 2019). This activity persisted for 5 weeks as a hallmark of neuronal hyperactivity associated with ongoing pain (B, bottom). Alternatively, GECl-expressing transgenic mice allow the study of excitatory and inhibitory synchronization properties of anesthetized and awake (B, top) animals (Knoblich et al., 2019).

Generation of conditional mouse reporter of calcium facilitated the deployment of GECI in microglia, permitting in vivo studies of intracellular calcium in large microglial cell populations in cerebral pathologies such as ischemic stroke. The use of reporter mice and recent GECI indicated novel roles in development and plasticity-driven reorganization, as well as a surveillant cell in the homeostatic maintenance of brain tissue (Brawek and Garaschuk, 2013); large cell populations have been imaged in ischemic stroke in vivo (Tvrdik et al., 2019).

One of the hottest topics in the last decade related to microglia is the role in neural circuits refinement via both promoting synapse formation and by targeting specific synapses for elimination and phagocytosis (Akiyoshi et al., 2018). $\mathrm{Ca}^{2+}$ imaging of larger populations of motor cortical layer $2 / 3$ pyramidal neurons show microglia-dendritic spine interactions that increase neuronal activity and consequent neuronal synchronization in healthy brain in awake mice (Akiyoshi et al., 2018).

\section{CANCER}

\section{Glioblastoma as a Model}

Cancer affects millions worldwide and comprises a multifaceted pathology of different histopathological types. The cancer microenvironment has a unique scenario and shares common strategies for development. Therefore, the use of a methodology to selectively identify, differentiate, and gather information through a functional imaging property is highly desirable.

Glioblastoma multiforme is a grade IV malignant, astrocytederived brain tumor, highly heterogeneous, with unfavorable prognosis. Seizures are frequently seen among patients due to an imbalance in the inhibitory interneuron network and excess of glutamate release (Hatcher et al., 2020). In this sense, cell lines have been used to model glioblastoma and other high-grade gliomas, and calcium imaging has been applied as a strategy to evaluate receptors/transporters/exchangers from tumors and healthy cells. GL261 cell line has been used to match pharmacological treatments based on cellular phenotype, cultured under adherent or non-adherent conditions. Both ATP (through P2X7 receptor) and capsaicin (TRPV1 receptor) activate a strong calcium response in GL261 neurospheres, but not on adherent cells (Strong and Daniels, 2017). This cell line secretes glutamate upon ATP activation, which is excitotoxic to healthy tissue and linked to tumorigenicity into adjacent brain regions (Strong et al., 2018). In addition to P2X7 and TPRV receptors, the $\mathrm{Na}^{+} / \mathrm{Ca}^{2+}$ exchanger (NCX), when activated by SKF 96365 (TRPC channel blocker), increases $\mathrm{Ca}^{2+}$ levels in glioblastoma cells (Figure 4). NCX controls intracellular $\mathrm{Ca}^{2+}$ homeostasis, and silencing of NCX1 


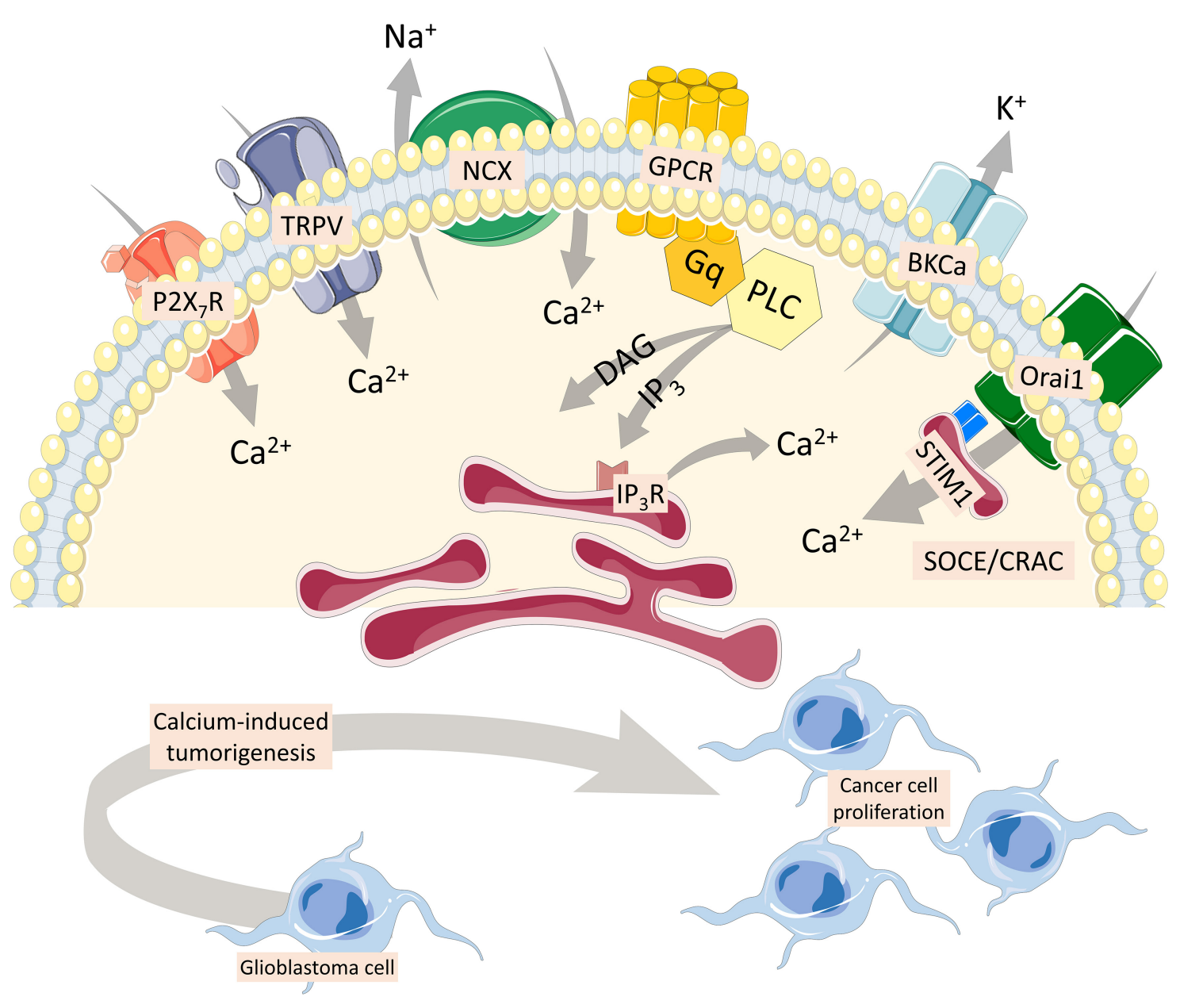

FIGURE 4 | Multiple $\mathrm{Ca}^{2+}$ pathways involved in cancer cells. P2X7 and TRPV1 receptors activate a strong calcium response in cancer cells (Strong and Daniels, 2017). Glutamate secretion upon ATP activation is excitotoxic to healthy tissue and linked to tumorigenicity into adjacent brain regions (Strong et al., 2018). The $\mathrm{Na}^{+} / \mathrm{Ca}^{2+}$ exchanger (NCX), which maintains cytoplasmic calcium homeostatic levels, also increases $\mathrm{Ca}^{2+}$ levels in glioblastoma cells (Song et al., 2014). Inhibition of the forward NCX $\left(\mathrm{Ca}^{2+}\right.$ exit mode) induces a $\mathrm{Ca}^{2+}$-mediated injury in glioblastoma cells (Hu et al., 2019). Finally, G protein-coupled metabotropic receptors coupled to activation of phospholipase $\mathrm{C}$ result in the generation of the second messenger, inositol 1,4,5 trisphosphate, which increases intracellular $\mathrm{Ca}^{2+}$ and diacylglycerol, involved in cancer cell proliferation, with important participation of the large-conductance voltage- and $\mathrm{Ca}^{2+}$-activated $\mathrm{K}^{+}$channel. Store-operated $\mathrm{Ca}^{2+}$ entry is mediated through $\mathrm{Ca}^{2+}$ release-activated $\mathrm{Ca}^{2+}$ current, composed by ORAl1, and stromal interaction molecule 1 (STIM-1), a luminal Ca ${ }^{2+}$ sensor transmembrane protein present in the endoplasmic reticulum membrane (Putney, 2009; De Bock et al., 2013). Both ORAl1 and STIM-1 are upregulated in primary human cell lines obtained from samples of glioblastoma (Motiani et al., 2013).

isoforms diminished the effect of SKF 96365 on glioblastoma cells (Song et al., 2014). In addition, inhibition of the forward NCX ( $\mathrm{Ca}^{2+}$ exit mode), with bepridil and CB-DMB, induced $\mathrm{Ca}^{2+}$-mediated injury in glioblastoma cells ( $\mathrm{Hu}$ et al., 2019). NCX maintains cytoplasmic calcium homeostatic levels, in addition to plasma membrane $\mathrm{Ca}^{2+}$ transport ATPase (PMCA) and sarco/endoplasmic reticulum (SR/ER) $\mathrm{Ca}^{2+}$ ATPase (SERCA).

The P2X7 receptor is found in several types of tumors, such as neuroblastoma, melanoma, prostate, lung, and breast cancer. P2X7 expression is commonly associated with cancer cell survival, proliferation, and metastatic potential; upon dysregulation, the $\mathrm{P} 2 \mathrm{X} 7$ receptor is associated with tumor initiation and development (Gilbert et al., 2019).
ING5, a member of the ING family of epigenetic regulators that alter histone acetylation and, subsequently, gene expression, increased the expression of stem cell markers and, consequently, brain tumor-initiating cells that cause the recurrence of glioblastomas (stemness) affected by epigenetic mechanisms (Wang F. et al., 2018). Proteomics and cell imaging assays demonstrated that ING5-transfected cells had intracellular $\mathrm{Ca}^{2+}$ elevation, which was associated with self-renewal, due to an increased expression of several types of $\mathrm{Ca}^{2+}$ channels, like L-type and P/Q-type voltage-gated $\mathrm{Ca}^{2+}$ channels, and TRPC (Wang F. et al., 2018). Differentiated glioblastoma cells constitute a distinctive niche compared to glioblastoma stem cells, sending cues to the microenvironment, both as juxtacrine (involving direct contact) or paracrine (through secreted factors). One of 
these is BDNF, secreted by SOX2-negative tumor cells (Wang X. et al., 2018). Activation of NTRK2, the cognate receptor, activates the PI3K-AKT pathway which is activated in glioblastoma stem cells, leading to tumor growth (Wang X. et al., 2018).

Store-operated $\mathrm{Ca}^{2+}$ entry (SOCE) is mediated through $\mathrm{Ca}^{2+}$ release-activated $\mathrm{Ca}^{2+}$ current (CRAC), non-voltage sensitive channels highly selective for $\mathrm{Ca}^{2+}$. They are composed by ORAI1, a member of the ORAI Ca ${ }^{2+}$ channel family (also known as CRAC modulator 1 or CRACM1), and form a macromolecular complex with the stromal interaction molecule 1 (STIM-1), a luminal $\mathrm{Ca}^{2+}$ sensor transmembrane protein present in the ER membrane (Putney, 2009; De Bock et al., 2013). Both ORAI1 and STIM-1 are upregulated in primary human cell lines obtained from surgical samples of glioblastoma multiforme compared to non-tumor human astrocytes (Motiani et al., 2013). CRAC inhibitors SKF-96365, 2-APB, and diethylstilbestrol also blocked GBM cell proliferation, and silencing of ORAI1 and STIM1 proteins using siRNA significantly inhibited C6 cell proliferation and SOCE compared to control cells (Liu et al., 2011).

Mice generated with CRISPR-based in utero electroporation of three deleted genes encoding phosphatase and tensin homolog (Pten), neurofibromin 1 (Nf1), and p53 (Trp53), all linked to tumorigenesis in human glioma genes, show a brain tumor with progressive cortical hyperexcitability due to tumor invasion and spontaneous seizures. $\mathrm{Iba}^{+}{ }^{+}$cells (microglia) also increased fivefold in the neighboring tumor area. Intracellular calcium imaging revealed recurrent seizure activity and robust bilateral calcium activity in GCAMP unanesthetized mice (Hatcher et al., 2020).

Metabotropic receptors coupled to the activation of phospholipase C (PLC) results in phosphatidylinositol 4,5 biphosphate cleavage and generation of the second messengers inositol 1,4,5 trisphosphate (IP3), which increases intracellular $\mathrm{Ca}^{2+}$, and diacylglycerol, which activates protein kinase C. Activation of IP3 receptors on intracellular stores (endoplasmic reticulum and calciosomes) permits the release of $\mathrm{Ca}^{2+}$ down its electrochemical gradient, reaching cytoplasmic levels up to $10^{-6} \mathrm{M}$ (Berridge et al., 2000). Type 3 IP3 receptor (IP3R3) and voltage- and $\mathrm{Ca}^{2+}$ dependent $\mathrm{K}(+)$ channels (BKCa) were shown to participate in breast cancer cell proliferation. Cell lines MCF-7 and MCF-10A are activated by $25 \mu \mathrm{M}$ ATP, which induces a PLC-dependent elevation of intracellular $\mathrm{Ca}^{2+}$ and cell proliferation, which is ablated when the expression of both $\mathrm{BKCa}$ and/or IP3R3 is inhibited by specific small interfering RNAs, leading to a cell cycle arrest in the G0/G1 phase (Mound et al., 2013). Alternatively, live-cell imaging of intracellular calcium fluxes has been used in human parathyroid tumor sections upon calcium-sensing receptor activation, a metabotropic receptor, and consequently visualize the effects of intratumoral heterogeneity in real time (Koh et al., 2017).

\section{NEURAL CELL LINEAGES DERIVED FROM IPS CELLS}

Induced pluripotent stem (iPS) cells have been generated from mouse and human somatic cells by introducing selective transcription factors (Oct3/4, Sox2, Klf4, c-Myc, Nanog, and/or Lin28) using retroviruses or lentiviruses (Okita et al., 2008). Differentiation of iPS on neural cells from self-organized human organoids/spheroids has recently been used to generate multiple classes of cells: progenitors, neurons, and glia to be enriched and considered to be used in healthy and disease models, such as neurological disorders. Indeed astrocyte (Dezonne et al., 2017; Sloan et al., 2017), oligodendrocyte (Marton et al., 2019) and neuron (Nascimento et al., 2019) lineage cells, as well as region-specific cortical neurons and astrocytes, some from both deep and superficial cortical layers that are transcriptionally correlated to in vivo fetal development (Paşca et al., 2015), have been generated following multiple strategies, of which functionality data included calcium imaging assays. Derived glia from human cerebral cortical spheroids had similar properties found in primary fetal astrocytes, and upon transition to a more developed state, dozens of astrocytic markers increased as expected, accelerating around birth, while fetal astrocyte markers declined rapidly over this same period. Gene analysis can be hierarchically organized and disposed as three primary clusters of cells: for instance, the expression levels of aquaporin-4, the transcription factor SOX9, and the glial high-affinity glutamate transporter were compatible to astrocyte lineage cells, but not neurons derived from spheroids (Sloan et al., 2017); changes in calcium signaling, phagocytic capacity, and transcriptional regulation approached to those observed in a mature state (Sloan et al., 2017). In general, emerging cortical organoids from iPS replicates most of the characteristics found in the in vivo cortex, including temporal corticogenesis and connectivity. The exception seems to be generation of microglia and blood vessels (Varrault et al., 2019). Co-cultures of astrocytes generated from human cerebral cortical spheroids in the presence of early in vitro-stage neurons produced an increase in depolarizationinduced calcium signaling (Sloan et al., 2017).

Electrophysiology is also a valuable tool to evaluate organoids at the molecular and the cellular levels, comparing gene expression profiles among fetal and adult brains using cerebral organoids (Logan et al., 2020). The activity of cultured neurons from human dissociated embryonic stem cell-derived cerebral organoids was also evaluated through calcium imaging, and the activities were shown to follow synchronized and nonsynchronized patterns (Sakaguchi et al., 2019). Part of this activity depends on gamma-aminobutyric acid (GABA) and gap junctions to the development of synchronous activity in hPSC-derived neural networks (Mäkinen et al., 2018). Human organoids are also being developed to model glioblastoma, so invasion can be studied and how tumorigenesis relates to the extracellular matrix can be understood (Silvia and Dai, 2020). Tumor cells within organoids extend a network of long microtubes, recapitulating the in vivo behavior of GBM (Krieger et al., 2020). The transcriptional changes implicated in the invasion process are coherent across patient samples, indicating that GBM cells reactively upregulate genes required for their dispersion.

Millions of chronic disease patients with organ insufficiency that cannot be treated with transplant or pharmacotherapy rely on the possibility that 1 day personalized-specific iPS cells might 
integrate in target tissues and become a routine in regenerative medicine. In terms of brain function, this type of approach is being used to treat ischemia to replenish neural cells and to approach autism spectral disorder as many proteins involved in the regulation of synaptic plasticity, neuronal excitability, and neuronal connectivity are inappropriately developmentally generated or misplaced, disturbing the neuronal network activity (Culotta and Penzes, 2020). On Alzheimer's disease, early hyperexcitability is linked to widespread synapse loss and cognitive dysfunction, and therefore a culture model derived from human cerebral organoids might shed some light on a synaptic plasticity model comparing aberrant neural networks from controls (Ghatak et al., 2020).

\section{FINAL REMARKS}

Calcium imaging has been used in diverse dynamic cellular networks to correlate spatiotemporal calcium shifts to different intracellular and extracellular mechanisms. The transition of progenitors and stem cells to differentiated neurons, astrocytes, oligodendrocytes, and microglia can be followed through ion

\section{REFERENCES}

Ahluwalia, J., Urban, L., Bevan, S., and Nagy, I. (2003). Anandamide regulates neuropeptide release from capsaicin-sensitive primary sensory neurons by activating both the cannabinoid 1 receptor and the vanilloid receptor 1 in vitro. Eur. J. Neurosci. 17, 2611-2618. doi: 10.1046/j.1460-9568.2003.02703.x

Ai, M., Mills, H., Kanai, M., Lai, J., Deng, J., Schreiter, E., et al. (2015). Green-toRed Photoconversion of GCaMP. PLoS One 10:e0138127. doi: 10.1371/journal. pone. 0138127

Akiyoshi, R., Wake, H., Kato, D., Horiuchi, H., Ono, R., Ikegami, A., et al. (2018). Microglia enhance synapse activity to promote local network synchronization. eNeuro 5:ENEURO.0088-18. doi: 10.1523/eneuro.0088-18.2018

Albers, F., Wachsmuth, L., van Alst, T. M., and Faber, C. (2018). Multimodal functional neuroimaging by simultaneous BOLD fMRI and Fiber-optic calcium recordings and optogenetic control. Mol. Imaging Biol. 20, 171-182. doi: 10. 1007/s11307-017-1130-6

Anderson, M., Zheng, Q., and Dong, X. (2018). Investigation of pain mechanisms by calcium imaging approaches. Neurosci. Bull. 34, 194-199. doi: 10.1007/ s12264-017-0139-9

Baden, T., Berens, P., Franke, K., Román Rosón, M., Bethge, M., and Euler, T. (2016). The functional diversity of retinal ganglion cells in the mouse. Nature 529, 345-350. doi: 10.1038/nature16468

Barnstable, C. J. (1993). Glutamate and GABA in retinal circuitry. Curr. Opin. Neurobiol. 3, 520-525. doi: 10.1016/0959-4388(93)90050-9

Berridge, M. J., Lipp, P., and Bootman, M. D. (2000). The versatility and universality of calcium signalling. Nat. Rev. Mol. Cell Biol. 1, 11-21. doi: 10. 1038/35036035

Brawek, B., and Garaschuk, O. (2013). Microglial calcium signaling in the adult, aged and diseased brain. Cell Calcium 53, 159-169. doi: 10.1016/j.ceca.2012. 12.003

Bruton, J., Cheng, A. J., and Westerblad, H. (2020). Measuring $\mathrm{Ca}(2+)$ in living cells. Adv. Exp. Med. Biol. 1131, 7-26. doi: 10.1007/978-3-030-12457-1_2

Carafoli, E., and Krebs, J. (2016). Why Calcium? How calcium became the best communicator. J. Biol. Chem. 291, 20849-20857. doi: 10.1074/jbc.R116.735894

Caterina, M. J., Schumacher, M. A., Tominaga, M., Rosen, T. A., Levine, J. D., and Julius, D. (1997). The capsaicin receptor: a heat-activated ion channel in the pain pathway. Nature 389, 816-824. doi: 10.1038/39807

Catterall, W. A. (2000). Structure and regulation of voltage-gated Ca2+ channels. Annu. Rev. Cell Dev. Biol. 16, 521-555. doi: 10.1146/annurev.cellbio.16.1.521 channels, transporters, and receptors coupled to calcium fluxes. Cancer cells or inducible pluripotent cell lines might help to model diseases and can be differentiated from healthy cells in terms of the expression of calcium-binding/permeable molecules and shed light on therapy.

\section{AUTHOR CONTRIBUTIONS}

RM, HF, and FM contributed to the review body text and the conception of the figures. All authors contributed to the article and approved the submitted version.

\section{FUNDING}

$\mathrm{HF}$ is a post-doctoral fellow at UC Davis. This work was supported by FAPERJ (Fundação Carlos Chagas Filho de Amparo à Pesquisa do Estado do Rio de Janeiro), CNPq (Conselho Nacional de Desenvolvimento Científico e Tecnològico; PQ fellowship 305784/2018-8), and INCT-INNT (National Institute of Translational Neuroscience 465346/2014-6).

Caval-Holme, F., Zhang, Y., and Feller, M. B. (2019). Gap junction coupling shapes the encoding of light in the developing retina. Curr. Biol. 29, 4024-4035.e5. doi: 10.1016/j.cub.2019.10.025

Chen, C., Zhang, J., Sun, L., Zhang, Y., Gan, W. B., Tang, P., et al. (2019). Long-term imaging of dorsal root ganglia in awake behaving mice. Nat. Commun. 10:3087. doi: 10.1038/s41467-019-11158-0

Chen, G., Zhang, Y. Q., Qadri, Y. J., Serhan, C. N., and Ji, R. R. (2018). Microglia in pain: detrimental and protective roles in pathogenesis and resolution of pain. Neuron 100, 1292-1311. doi: 10.1016/j.neuron.2018.11.009

Cook, N. D. (2008). The neuron-level phenomena underlying cognition and consciousness: synaptic activity and the action potential. Neuroscience 153, 556-570. doi: 10.1016/j.neuroscience.2008.02.042

Corder, G., Ahanonu, B., Grewe, B. F., Wang, D., Schnitzer, M. J., and Scherrer, G. (2019). An amygdalar neural ensemble that encodes the unpleasantness of pain. Science 363, 276-281. doi: 10.1126/science.aap8586

Coull, J. A., Boudreau, D., Bachand, K., Prescott, S. A., Nault, F., Sík, A., et al. (2003). Trans-synaptic shift in anion gradient in spinal lamina I neurons as a mechanism of neuropathic pain. Nature 424, 938-942. doi: 10.1038/ nature 01868

Coull, J. A. M., Beggs, S., Boudreau, D., Boivin, D., Tsuda, M., Inoue, K., et al. (2005). BDNF from microglia causes the shift in neuronal anion gradient underlying neuropathic pain. Nature 438, 1017-1021. doi: 10.1038/ nature 04223

Culotta, L., and Penzes, P. (2020). Exploring the mechanisms underlying excitation/inhibition imbalance in human iPSC-derived models of ASD. Mol. Autism 11:32. doi: 10.1186/s13229-020-00339-0

David, S., and Kroner, A. (2011). Repertoire of microglial and macrophage responses after spinal cord injury. Nat. Rev. Neurosci. 12, 388-399. doi: 10.1038/ nrn3053

De Bock, M., Wang, N., Decrock, E., Bol, M., Gadicherla, A. K., Culot, M., et al. (2013). Endothelial calcium dynamics, connexin channels and blood-brain barrier function. Prog. Neurobiol. 108, 1-20. doi: 10.1016/j.pneurobio.2013. 06.001

De Melo Reis, R. A., Schitine, C. S., Kofalvi, A., Grade, S., Cortes, L., Gardino, P. F., et al. (2011). Functional identification of cell phenotypes differentiating from mice retinal neurospheres using single cell calcium imaging. Cell. Mol. Neurobiol. 31, 835-846. doi: 10.1007/s10571-011-9673-6

de Melo Reis, R. A., Ventura, A. L., Schitine, C. S., de Mello, M. C., and de Mello, F. G. (2008). Muller glia as an active compartment modulating nervous activity 
in the vertebrate retina: neurotransmitters and trophic factors. Neurochem. Res. 33, 1466-1474. doi: 10.1007/s11064-008-9604-1

Dezonne, R. S., Sartore, R. C., Nascimento, J. M., Saia-Cereda, V. M., Romão, L. F., Alves-Leon, S. V., et al. (2017). Derivation of functional human astrocytes from cerebral organoids. Sci. Rep. 7:45091. doi: 10.1038/srep45091

Eiriz, M. F., Grade, S., Rosa, A., Xapelli, S., Bernardino, L., Agasse, F., et al. (2011). Functional evaluation of neural stem cell differentiation by single cell calcium imaging. Curr. Stem Cell Res. Ther. 6, 288-296. doi: 10.2174/ 157488811796575387

Faria, R. X., Freitas, H. R., and Reis, R. A. M. (2017). P2X7 receptor large pore signaling in avian Muller glial cells. J. Bioenerg. Biomembr. 49, 215-229. doi: 10.1007/s10863-017-9717-9

Fields, R. D., and Burnstock, G. (2006). Purinergic signalling in neuron-glia interactions. Nat. Rev. Neurosci. 7, 423-436. doi: 10.1038/nrn1928

Frackowiak, R., and Markram, H. (2015). The future of human cerebral cartography: a novel approach. Philos. Trans. R. Soc. Lond. B Biol. Sci. 370:20140171. doi: 10.1098/rstb.2014.0171

Freitas, H. R., Ferraz, G., Ferreira, G. C., Ribeiro-Resende, V. T., Chiarini, L. B., do Nascimento, J. L., et al. (2016). Glutathione-induced calcium shifts in chick retinal glial cells. PLoS One 11:e0153677. doi: 10.1371/journal.pone.01 53677

Freitas, H. R., Isaac, A. R., Silva, T. M., Diniz, G. O. F., Dos Santos Dabdab, Y., Bockmann, E. C., et al. (2019). Cannabinoids induce cell death and promote P2X7 receptor signaling in retinal glial progenitors in culture. Mol. Neurobiol. 56, 6472-6486. doi: 10.1007/s12035-019-1537-y

Freitas, H. R., and Reis, R. A. (2017). Glutathione induces GABA release through P2X7R activation on Muller glia. Neurogenesis 4:e1283188. doi: 10.1080/ 23262133.2017.1283188

Ganguly, K., Schinder, A. F., Wong, S. T., and Poo, M. (2001). GABA itself promotes the developmental switch of neuronal GABAergic responses from excitation to inhibition. Cell 105, 521-532. doi: 10.1016/s0092-8674(01) 00341-5

Ghatak, S., Dolatabadi, N., Gao, R., Wu, Y., Scott, H., Trudler, D., et al. (2020). NitroSynapsin ameliorates hypersynchronous neural network activity in Alzheimer hiPSC models. Mol Psychiatry. doi: 10.1038/s41380-020-0776-7 [Epub ahead of print].

Gilbert, S. M., Oliphant, C. J., Hassan, S., Peille, A. L., Bronsert, P., Falzoni, S., et al. (2019). ATP in the tumour microenvironment drives expression of $\operatorname{nfP} 2 \mathrm{X}(7)$, a key mediator of cancer cell survival. Oncogene 38, 194-208. doi: 10.1038/ s41388-018-0426-6

Grienberger, C., and Konnerth, A. (2012). Imaging calcium in neurons. Neuron 73, 862-885. doi: 10.1016/j.neuron.2012.02.011

Grynkiewicz, G., Poenie, M., and Tsien, R. Y. (1985). A new generation of Ca2+ indicators with greatly improved fluorescence properties. J. Biol. Chem. 260, 3440-3450.

Guan, J., Li, J., Liang, S., Li, R., Li, X., Shi, X., et al. (2018). NeuroSeg: automated cell detection and segmentation for in vivo two-photon $\mathrm{Ca}(2+)$ imaging data. Brain Struct. Funct. 223, 519-533. doi: 10.1007/s00429-017-1545-5

Guimaraes, M. Z., Hokoc, J. N., Duvoisin, R., Reis, R. A., and De Mello, F. G. (2001). Dopaminergic retinal cell differentiation in culture: modulation by forskolin and dopamine. Eur. J. Neurosci. 13, 1931-1937. doi: 10.1046/j.0953-816x.2001. 01575.x

Guimaraes, R. P. M., Landeira, B. S., Coelho, D. M., Golbert, D. C. F., Silveira, M. S., Linden, R., et al. (2018). Evidence of Muller glia conversion into retina ganglion cells using neurogenin2. Front. Cell. Neurosci. 12:410. doi: 10.3389/fncel.2018. 00410

Guo, Q., Zhou, J., Feng, Q., Lin, R., Gong, H., Luo, Q., et al. (2015). Multichannel fiber photometry for population neuronal activity recording. Biomed. Opt. Express 6, 3919-3931. doi: 10.1364/boe.6.003919

Hampton, T. (2018). Researchers reprogram cells in vivo to restore vision in mice. JAMA 320, 1745-1745. doi: 10.1001/jama.2017.12866

Hatakeyama, J., and Kageyama, R. (2004). Retinal cell fate determination and bHLH factors. Semin. Cell Dev. Biol. 15, 83-89. doi: 10.1016/j.semcdb.2003. 09.005

Hatcher, A., Yu, K., Meyer, J., Aiba, I., Deneen, B., and Noebels, J. L. (2020). Pathogenesis of peritumoral hyperexcitability in an immunocompetent CRISPR-based glioblastoma model. J. Clin. Invest. 130, 2286-2300. doi: 10. 1172/JCI133316
Hong, G., Fu, T.-M., Qiao, M., Viveros, R. D., Yang, X., Zhou, T., et al. (2018). A method for single-neuron chronic recording from the retina in awake mice. Science 360, 1447-1451. doi: 10.1126/science.aas9160

Hu, H.-J., Wang, S.-S., Wang, Y.-X., Liu, Y., Feng, X.-M., Shen, Y., et al. (2019). Blockade of the forward $\mathrm{Na}(+) / \mathrm{Ca}(2+)$ exchanger suppresses the growth of glioblastoma cells through $\mathrm{Ca}(2+)$-mediated cell death. Br. J. Pharmacol. 176, 2691-2707. doi: 10.1111/bph.14692

Hu, X., Liu, Y., Wu, J., Liu, Y., Liu, W., Chen, J., et al. (2020). Inhibition of P2X7R in the amygdala ameliorates symptoms of neuropathic pain after spared nerve injury in rats. Brain Behav. Immun. 88, 507-514. doi: 10.1016/j.bbi.2020.04.030

Inoue, M. (2020). Genetically encoded calcium indicators to probe complex brain circuit dynamics in vivo. Neurosci. Res. doi: 10.1016/j.neures.2020.05.013 [Epub ahead of print].

Islam, M. S. (2020). Calcium signaling: from basic to bedside. Adv. Exp. Med. Biol. 1131, 1-6. doi: 10.1007/978-3-030-12457-1_1

Johannssen, H. C., and Helmchen, F. (2010). In vivo Ca2+ imaging of dorsal horn neuronal populations in mouse spinal cord. J. Physiol. 588(Pt 18), 3397-3402. doi: 10.1113/jphysiol.2010.191833

Kaifosh, P., Zaremba, J. D., Danielson, N. B., and Losonczy, A. (2014). SIMA: python software for analysis of dynamic fluorescence imaging data. Front. Neuroinform. 8:80. doi: 10.3389/fninf.2014.00080

Keirstead, S. A., and Miller, R. F. (1997). Metabotropic glutamate receptor agonists evoke calcium waves in isolated Müller cells. Glia 21, 194-203.

Kim, C. K., Adhikari, A., and Deisseroth, K. (2017). Integration of optogenetics with complementary methodologies in systems neuroscience. Nat. Rev. Neurosci. 18, 222-235. doi: 10.1038/nrn.2017.15

Knoblich, U., Huang, L., Zeng, H., and Li, L. (2019). Neuronal cell-subtype specificity of neural synchronization in mouse primary visual cortex. Nat. Commun. 10:2533. doi: 10.1038/s41467-019-10498-1

Koh, J., Hogue, J. A., and Sosa, J. A. (2017). Live-cell visualization of calcium flux in vibratome-cut thick sections of viable tumor tissue. Curr. Protoc. Cell Biol. 77, 4.34.1-4.34.16. doi: 10.1002/cpcb.37

Krieger, T. G., Tirier, S. M., Park, J., Jechow, K., Eisemann, T., Peterziel, H., et al. (2020). Modeling glioblastoma invasion using human brain organoids and single-cell transcriptomics. Neuro Oncol. 22, 1138-1149. doi: 10.1093/neuonc/ noaa091

Kroner, A., and Rosas Almanza, J. (2019). Role of microglia in spinal cord injury. Neurosci. Lett. 709:134370. doi: 10.1016/j.neulet.2019.134370

Kubrusly, R. C. C., Gunter, A., Sampaio, L., Martins, R. S., Schitine, C. S., Trindade, P., et al. (2018). Neuro-glial cannabinoid receptors modulate signaling in the embryonic avian retina. Neurochem. Int. 112, 27-37. doi: 10.1016/j.neuint.2017. 10.016

Lake, E. M. R., Ge, X., Shen, X., Herman, P., Hyder, F., Cardin, J., et al. (2018). Simultaneous mesoscopic $\mathrm{Ca} 2+$ imaging and fMRI: neuroimaging spanning spatiotemporal scales. bioRxiv [Preprint]. doi: 10.1101/464305

Liang, Z., Ma, Y., Watson, G. D. R., and Zhang, N. (2017). Simultaneous GCaMP6based fiber photometry and fMRI in rats. J. Neurosci. Methods 289, 31-38. doi: 10.1016/j.jneumeth.2017.07.002

Lichtman, J. W., Livet, J., and Sanes, J. R. (2008). A technicolour approach to the connectome. Nat. Rev. Neurosci. 9, 417-422. doi: 10.1038/nrn2391

Liu, H., Hughes, J. D., Rollins, S., Chen, B., and Perkins, E. (2011). Calcium entry via ORAI1 regulates glioblastoma cell proliferation and apoptosis. Exp. Mol. Pathol. 91, 753-760. doi: 10.1016/j.yexmp.2011.09.005

Logan, S., Arzua, T., Yan, Y., Jiang, C., Liu, X., Yu, L. K., et al. (2020). Dynamic characterization of structural, molecular, and electrophysiological phenotypes of human-induced pluripotent stem cell-derived cerebral organoids, and comparison with fetal and adult gene profiles. Cells 9:1301. doi: 10.3390/ cells 9051301

Logothetis, N. K., Pauls, J., Augath, M., Trinath, T., and Oeltermann, A. (2001). Neurophysiological investigation of the basis of the fMRI signal. Nature 412, 150-157. doi: 10.1038/35084005

Mäkinen, M. E.-L., Ylä-Outinen, L., and Narkilahti, S. (2018). GABA and Gap junctions in the development of synchronized activity in human pluripotent stem cell-derived neural networks. Front. Cell. Neurosci. 12:56. doi: 10.3389/ fncel.2018.00056

Mapplebeck, J. C. S., Dalgarno, R., Tu, Y., Moriarty, O., Beggs, S., Kwok, C. H. T., et al. (2018). Microglial P2X4R-evoked pain hypersensitivity is sexually dimorphic in rats. Pain 159, 1752-1763. 
Marton, R. M., Miura, Y., Sloan, S. A., Li, Q., Revah, O., Levy, R. J., et al. (2019). Differentiation and maturation of oligodendrocytes in human threedimensional neural cultures. Nat. Neurosci. 22, 484-491. doi: 10.1038/s41593018-0316-9

Metea, M. R., and Newman, E. A. (2006). Calcium signaling in specialized glial cells. Glia 54, 650-655. doi: 10.1002/glia.20352

Miller, D. J. (2004). Sydney Ringer; physiological saline, calcium and the contraction of the heart. J. Physiol. 555(Pt 3), 585-587. doi: 10.1113/jphysiol. 2004.060731

Millns, P. J., Chimenti, M., Ali, N., Ryland, E., De Lago, E., Fernandez-Ruiz, J., et al. (2006). Effects of inhibition of fatty acid amide hydrolase vs. the anandamide membrane transporter on TRPV1-mediated calcium responses in adult DRG neurons; the role of CB1 receptors. Eur. J. Neurosci. 24, 3489-3495. doi: 10.1111/j.1460-9568.2006.05236.x

Miyawaki, A., Llopis, J., Heim, R., McCaffery, J. M., Adams, J. A., Ikura, M., et al. (1997). Fluorescent indicators for Ca2+based on green fluorescent proteins and calmodulin. Nature 388, 882-887. doi: 10.1038/42264

Motiani, R. K., Hyzinski-Garcia, M. C., Zhang, X., Henkel, M. M., Abdullaev, I. F., Kuo, Y. H., et al. (2013). STIM1 and Orail mediate CRAC channel activity and are essential for human glioblastoma invasion. Pflugers Arch. 465, 1249-1260. doi: 10.1007/s00424-013-1254-8

Mound, A., Rodat-Despoix, L., Bougarn, S., Ouadid-Ahidouch, H., and Matifat, F. (2013). Molecular interaction and functional coupling between type 3 inositol 1,4,5-trisphosphate receptor and BKCa channel stimulate breast cancer cell proliferation. Eur. J. Cancer 49, 3738-3751. doi: 10.1016/j.ejca.2013.07.013

Mukamel, E. A., Nimmerjahn, A., and Schnitzer, M. J. (2009). Automated analysis of cellular signals from large-scale calcium imaging data. Neuron 63, 747-760. doi: 10.1016/j.neuron.2009.08.009

Nakai, J., Ohkura, M., and Imoto, K. (2001). A high signal-to-noise Ca(2+) probe composed of a single green fluorescent protein. Nat. Biotechnol. 19, 137-141. doi: $10.1038 / 84397$

Nascimento, J. M., Saia-Cereda, V. M., Sartore, R. C., da Costa, R. M., Schitine, C. S., Freitas, H. R., et al. (2019). Human cerebral organoids and fetal brain tissue share proteomic similarities. Front. Cell Dev. Biol. 7:303. doi: 10.3389/ fcell.2019.00303

Nimmerjahn, A., and Bergles, D. E. (2015). Large-scale recording of astrocyte activity. Curr. Opin. Neurobiol. 32, 95-106. doi: 10.1016/j.conb.2015.01.015

O’Hashi, K., Sohya, K., Matsuno, H., Tsuchimine, S., and Kunugi, H. (2019). Construction of the common cortical space by spontaneous activity and its application in the mouse cortex. Biochem. Biophys. Res. Commun. 513, 869-874. doi: 10.1016/j.bbrc.2019.04.048

Oheim, M., Schmidt, E., and Hirrlinger, J. (2018). Local energy on demand: are 'spontaneous' astrocytic $\mathrm{Ca}(2+)$-microdomains the regulatory unit for astrocyte-neuron metabolic cooperation? Brain Res. Bull. 136, 54-64. doi: 10. 1016/j.brainresbull.2017.04.011

Ohshiro, H., Ogawa, S., and Shinjo, K. (2007). Visualizing sensory transmission between dorsal root ganglion and dorsal horn neurons in co-culture with calcium imaging. J. Neurosci. Methods 165, 49-54. doi: 10.1016/j.jneumeth. 2007.05.018

Okada, T., Schultz, K., Geurtz, W., Hatt, H., and Weiler, R. (1999). AMPApreferring receptors with high $\mathrm{Ca} 2+$ permeability mediate dendritic plasticity of retinal horizontal cells. Eur. J. Neurosci. 11, 1085-1095. doi: 10.1046/j.14609568.1999.00516.x

Okita, K., Nakagawa, M., Hyenjong, H., Ichisaka, T., and Yamanaka, S. (2008). Generation of mouse induced pluripotent stem cells without viral vectors. Science 322, 949-953. doi: 10.1126/science.1164270

Oliveira-Fusaro, M. C. G., Zanoni, C. I. S., Dos Santos, G. G., Manzo, L. P., Araldi, D., Bonet, I. J. M., et al. (2017). Antihyperalgesic effect of CB(1) receptor activation involves the modulation of $\mathrm{P} 2 \mathrm{X}(3)$ receptor in the primary afferent neuron. Eur. J. Pharmacol. 798, 113-121. doi: 10.1016/j.ejphar.2017.01.030

Park, H., and Kim, J. E. (2020). Deletion of P2X7 receptor decreases basal glutathione level by changing glutamate-glutamine cycle and neutral amino acid transporters. Cells 9:995. doi: 10.3390/cells9040995

Paşca, A. M., Sloan, S. A., Clarke, L. E., Tian, Y., Makinson, C. D., Huber, N., et al. (2015). Functional cortical neurons and astrocytes from human pluripotent stem cells in 3D culture. Nat. Methods 12, 671-678. doi: 10.1038/nmeth.3415
Passos, A., Herculano, A. M., Oliveira, K., de Lima, S. M. A., Rocha, F. A. F., Freitas, H. R., et al. (2019). Regulation of the serotonergic system by kainate in the avian retina. Cell. Mol. Neurobiol. 39, 1039-1049. doi: 10.1007/s10571-019-00701-8

Peirs, C., and Seal, R. P. (2016). Neural circuits for pain: recent advances and current views. Science 354, 578-584. doi: 10.1126/science.aaf8933

Pnevmatikakis, E. A., and Giovannucci, A. (2017). NoRMCorre: an online algorithm for piecewise rigid motion correction of calcium imaging data. J. Neurosci. Methods 291, 83-94. doi: 10.1016/j.jneumeth.2017.07.031

Putney, J. W. (2009). Capacitative calcium entry: from concept to molecules. Immunol. Rev. 231, 10-22. doi: 10.1111/j.1600-065X.2009.00810.x

Ran, C., Hoon, M. A., and Chen, X. (2016). The coding of cutaneous temperature in the spinal cord. Nat. Neurosci. 19, 1201-1209. doi: 10.1038/nn.4350

Reichenbach, A., and Bringmann, A. (2013). New functions of Muller cells. Glia 61, 651-678. doi: 10.1002/glia.22477

Reichenbach, A., and Bringmann, A. (2016). Role of purines in muller glia. J. Ocul. Pharmacol. Ther. 32, 518-533. doi: 10.1089/jop.2016.0131

Reis, R. A., Ventura, A. L., Kubrusly, R. C., de Mello, M. C., and de Mello, F. G. (2007). Dopaminergic signaling in the developing retina. Brain Res. Rev. 54, 181-188. doi: 10.1016/j.brainresrev.2007.01.001

Ribeiro-Resende, V. T., Araujo Gomes, T., de Lima, S., Nascimento-Lima, M., Bargas-Rega, M., Santiago, M. F., et al. (2014). Mice lacking GD3 synthase display morphological abnormalities in the sciatic nerve and neuronal disturbances during peripheral nerve regeneration. PLoS One 9:e108919. doi: 10.1371/journal.pone.0108919

Rice, M. E., and Russo-Menna, I. (1998). Differential compartmentalization of brain ascorbate and glutathione between neurons and glia. Neuroscience 82, 1213-1223. doi: 10.1016/s0306-4522(97)00347-3

Ringer, S., and Buxton, D. W. (1887). Concerning the action of calcium, potassium, and sodium salts upon the eel's heart and upon the skeletal muscles of the frog. J. Physiol. 8, 15-19. doi: 10.1113/jphysiol.1887.sp000239

Rosa, J. M., Bos, R., Sack, G. S., Fortuny, C., Agarwal, A., Bergles, D. E., et al. (2015). Neuron-glia signaling in developing retina mediated by neurotransmitter spillover. eLife 4:e09590. doi: 10.7554/eLife.09590

Rudolf, R., Mongillo, M., Rizzuto, R., and Pozzan, T. (2003). Looking forward to seeing calcium. Nat. Rev. Mol. Cell Biol. 4, 579-586. doi: 10.1038/nrm1153

Russell, J. T. (2011). Imaging calcium signals in vivo: a powerful tool in physiology and pharmacology. Br. J. Pharmacol. 163, 1605-1625. doi: 10.1111/j.1476-5381. 2010.00988.x

Sakaguchi, H., Ozaki, Y., Ashida, T., Matsubara, T., Oishi, N., Kihara, S., et al. (2019). Self-organized synchronous calcium transients in a cultured human neural network derived from cerebral organoids. Stem Cell Rep. 13, 458-473. doi: 10.1016/j.stemcr.2019.05.029

Sargoy, A., Barnes, S., Brecha, N. C., and Pérez De Sevilla Müller, L. (2014). Immunohistochemical and calcium imaging methods in wholemount rat retina. J. Vis. Exp. 92:e51396. doi: 10.3791/51396

Schitine, C., Xapelli, S., Agasse, F., Sarda-Arroyo, L., Silva, A. P., De Melo Reis, R. A., et al. (2012). Ampakine CX546 increases proliferation and neuronal differentiation in subventricular zone stem/progenitor cell cultures. Eur. J. Neurosci. 35, 1672-1683. doi: 10.1111/j.1460-9568.2012.08072.x

Schitine, C. S., Mendez-Flores, O. G., Santos, L. E., Ornelas, I., Calaza, K. C., PerezToledo, K., et al. (2015). Functional plasticity of GAT-3 in avian Muller cells is regulated by neurons via a glutamatergic input. Neurochem. Int. 82, 42-51. doi: 10.1016/j.neuint.2015.02.004

Schlegel, F., Sych, Y., Schroeter, A., Stobart, J., Weber, B., Helmchen, F., et al. (2018). Fiber-optic implant for simultaneous fluorescence-based calcium recordings and BOLD fMRI in mice. Nat. Protoc. 13, 840-855. doi: 10.1038/ nprot.2018.003

Schulz, K., Sydekum, E., Krueppel, R., Engelbrecht, C. J., Schlegel, F., Schröter, A., et al. (2012). Simultaneous BOLD fMRI and fiber-optic calcium recording in rat neocortex. Nat. Methods 9, 597-602. doi: 10.1038/nmeth.2013

Sekaran, S., Foster, R. G., Lucas, R. J., and Hankins, M. W. (2003). Calcium imaging reveals a network of intrinsically light-sensitive inner-retinal neurons. Curr. Biol. 13, 1290-1298. doi: 10.1016/S0960-9822(03)00510-4

Sekiguchi, K. J., Shekhtmeyster, P., Merten, K., Arena, A., Cook, D., Hoffman, E., et al. (2016). Imaging large-scale cellular activity in spinal cord of freely behaving mice. Nat. Commun. 7, 11450-11450. doi: 10.1038/ncomms11450 
Silvia, N., and Dai, G. (2020). Cerebral organoids as a model for glioblastoma multiforme. Curr. Opin. Biomed. Eng. 13, 152-159. doi: 10.1016/j.cobme.2020. 03.004

Sloan, S. A., Darmanis, S., Huber, N., Khan, T. A., Birey, F., Caneda, C., et al. (2017). Human astrocyte maturation captured in 3D cerebral cortical spheroids derived from pluripotent stem cells. Neuron 95, 779-790.e6. doi: 10.1016/j.neuron.2017. 07.035

Soltanian-Zadeh, S., Sahingur, K., Blau, S., Gong, Y., and Farsiu, S. (2019). Fast and robust active neuron segmentation in two-photon calcium imaging using spatiotemporal deep learning. Proc. Natl. Acad. Sci. U.S.A. 116, 8554-8563. doi: 10.1073/pnas.1812995116

Song, M., Chen, D., and Yu, S. P. (2014). The TRPC channel blocker SKF 96365 inhibits glioblastoma cell growth by enhancing reverse mode of the $\mathrm{Na}(+)$ $/ \mathrm{Ca}(2+)$ exchanger and increasing intracellular $\mathrm{Ca}(2+)$. Br. J. Pharmacol. 171, 3432-3447. doi: 10.1111/bph.12691

Strong, A. D., and Daniels, R. L. (2017). Live-cell calcium imaging of adherent and non-adherent GL261 cells reveals phenotype-dependent differences in drug responses. BMC Cancer 17:516. doi: 10.1186/s12885-017-3507-y

Strong, A. D., Indart, M. C., Hill, N. R., and Daniels, R. L. (2018). GL261 glioma tumor cells respond to ATP with an intracellular calcium rise and glutamate release. Mol. Cell. Biochem. 446, 53-62. doi: 10.1007/s11010-018-3272-5

Sych, Y., Chernysheva, M., Sumanovski, L. T., and Helmchen, F. (2019). Highdensity multi-fiber photometry for studying large-scale brain circuit dynamics. Nat. Methods 16, 553-560. doi: 10.1038/s41592-019-0400-4

Thrane, A. S., Rangroo Thrane, V., Zeppenfeld, D., Lou, N., Xu, Q., Nagelhus, E. A., et al. (2012). General anesthesia selectively disrupts astrocyte calcium signaling in the awake mouse cortex. Proc. Natl. Acad. Sci. U.S.A. 109, 18974-18979. doi: 10.1073/pnas.1209448109

Tong, C., Dai, J. K., Chen, Y., Zhang, K., Feng, Y., and Liang, Z. (2019). Differential coupling between subcortical calcium and BOLD signals during evoked and resting state through simultaneous calcium fiber photometry and fMRI. Neuroimage 200, 405-413. doi: 10.1016/j.neuroimage.2019.07.006

Tsien, R. Y. (1980). New calcium indicators and buffers with high selectivity against magnesium and protons: design, synthesis, and properties of prototype structures. Biochemistry 19, 2396-2404. doi: 10.1021/bi00552a018

Tsien, R. Y., Pozzan, T., and Rink, T. J. (1982). Calcium homeostasis in intact lymphocytes: cytoplasmic free calcium monitored with a new, intracellularly trapped fluorescent indicator. J. Cell Biol. 94, 325-334. doi: 10.1083/jcb.94.2.325

Tsuda, M., Shigemoto-Mogami, Y., Koizumi, S., Mizokoshi, A., Kohsaka, S., Salter, M. W., et al. (2003). P2X4 receptors induced in spinal microglia gate tactile allodynia after nerve injury. Nature 424, 778-783. doi: 10.1038/nature 01786

Turner, D. L., and Cepko, C. L. (1987). A common progenitor for neurons and glia persists in rat retina late in development. Nature 328, 131-136. doi: 10.1038/ 328131a0

Tvrdik, P., Kearns, K. N., Sharifi, K. A., Sluzewski, M. F., Acton, S. T., and Kalani, M. Y. S. (2019). Calcium imaging of microglial network activity in stroke. Methods Mol. Biol. 2034, 267-279. doi: 10.1007/978-1-4939-9658-2_19

van der Stelt, M., Trevisani, M., Vellani, V., De Petrocellis, L., Schiano Moriello, A., Campi, B., et al. (2005). Anandamide acts as an intracellular messenger amplifying Ca2+ influx via TRPV1 channels. EMBO J. 24, 3026-3037. doi: 10.1038/sj.emboj.7600784
Varella, M. H., de Mello, F. G., and Linden, R. (1999). Evidence for an antiapoptotic role of dopamine in developing retinal tissue. J. Neurochem. 73, 485-492. doi: 10.1046/j.1471-4159.1999.0730485.x

Varrault, A., Journot, L., and Bouschet, T. (2019). Cerebral cortex generated from pluripotent stem cells to model corticogenesis and rebuild cortical circuits: In vitro veritas? Stem Cells Dev. 28, 361-369. doi: 10.1089/scd.2018.0233

Veruki, M. L., Zhou, Y., Castilho, Á, Morgans, C. W., and Hartveit, E. (2019). Extrasynaptic NMDA receptors on rod pathway amacrine cells: molecular composition, activation, and signaling. J. Neurosci 39, 627-650. doi: 10.1523/ jneurosci.2267-18.2018

Wang, F., Wang, A. Y., Chesnelong, C., Yang, Y., Nabbi, A., Thalappilly, S., et al. (2018). ING5 activity in self-renewal of glioblastoma stem cells via calcium and follicle stimulating hormone pathways. Oncogene 37, 286-301. doi: 10.1038/ onc.2017.324

Wang, M., He, Y., Sejnowski, T. J., and Yu, X. (2018). Brain-state dependent astrocytic $\mathrm{Ca}(2+)$ signals are coupled to both positive and negative BOLDfMRI signals. Proc. Natl. Acad. Sci. U.S.A. 115, E1647-E1656. doi: 10.1073/pnas. 1711692115

Wang, X., Prager, B. C., Wu, Q., Kim, L. J. Y., Gimple, R. C., Shi, Y., et al. (2018). Reciprocal signaling between glioblastoma stem cells and differentiated tumor cells promotes malignant progression. Cell Stem Cell 22, 514-528.e5. doi: 10.1016/j.stem.2018.03.011

Warbrick, T., Rosenberg, J., and Shah, N. J. (2017). The relationship between BOLD fMRI response and the underlying white matter as measured by fractional anisotropy (FA): a systematic review. Neuroimage 153, 369-381. doi: 10.1016/ j.neuroimage.2016.12.075

Wright, P. W., Brier, L. M., Bauer, A. Q., Baxter, G. A., Kraft, A. W., Reisman, M. D., et al. (2017). Functional connectivity structure of cortical calcium dynamics in anesthetized and awake mice. PLoS One 12:e0185759. doi: 10.1371/journal. pone.0185759

Xapelli, S., Agasse, F., Grade, S., Bernardino, L., Ribeiro, F. F., Schitine, C. S., et al. (2014). Modulation of subventricular zone oligodendrogenesis: A role for hemopressin? Front. Cell. Neurosci. 8:59. doi: 10.3389/fncel.2014. 00059

Xapelli, S., Agasse, F., Sarda-Arroyo, L., Bernardino, L., Santos, T., Ribeiro, F. F., et al. (2013). Activation of type 1 cannabinoid receptor (CB1R) promotes neurogenesis in murine subventricular zone cell cultures. PLoS One 8:e63529. doi: 10.1371/journal.pone.0063529

Yang, X. L. (2004). Characterization of receptors for glutamate and GABA in retinal neurons. Prog. Neurobiol. 73, 127-150. doi: 10.1016/j.pneurobio.2004.04.002

Conflict of Interest: The authors declare that the research was conducted in the absence of any commercial or financial relationships that could be construed as a potential conflict of interest.

Copyright (c) 2020 de Melo Reis, Freitas and de Mello. This is an open-access article distributed under the terms of the Creative Commons Attribution License (CC BY). The use, distribution or reproduction in other forums is permitted, provided the original author(s) and the copyright owner(s) are credited and that the original publication in this journal is cited, in accordance with accepted academic practice. No use, distribution or reproduction is permitted which does not comply with these terms. 